\title{
Cell type-specific monoclonal antibody
}

\section{cross-reactivity screening in non-human primates and development of comparative}

\section{immunophenotyping panels for CyTOF}

Zachary B Bjornson-Hooper*, Gabriela K Fragiadakis*, Matthew H Spitzer*†, Deepthi Madhireddy*, Kevin Huキ, Kelly Lundsten§, Garry P Nolan* *Stanford University School of Medicine, Baxter Laboratory for Stem Cell Biology.

tImmunology Program, Stanford University; Department of Otolaryngology - Head and Neck Surgery and Microbiology \& Immunology, University of California, San Francisco; Parker Institute for Cancer Immunotherapy; Chan Zuckerberg Biohub.

¥Massachusetts Institute of Technology.

§BioLegend Inc.

Monoclonal antibodies are a critical tool for immunologists, with applications including immunomicroscopy and cytometry, and non-human primates are essential models for drug development. Very few antibodies are raised against non-human primate antigens; instead, researchers typically use anti-human antibodies that are found to be cross-reactive with non-human primates. The NIH maintains a valuable database of cross-reactivity, but its coverage is not complete, especially for less common species. Furthermore, the database only indicates the presence or absence of staining and does not indicate if a different cell population is stained in the NHP species than in humans. We screened 332 antibodies in five immune cell populations in blood from cynomologus macaques (Macaca fascicularis), rhesus macaques (Macaca mulatta), African green monkeys (Chlorocebus aethiops) and olive/yellow baboons (Papio hamadryas anubis x Papio hamadryas cynocephalus), thereby generating a comprehensive cross-reactivity catalog that includes cell type-specificity. We subsequently used this catalog to help create large CyTOF mass cytometry panels for three of those species and humans. The curated dataset containing the primary data for each antibody has been deposited as a browsable resource at https://immuneatlas.org and https://flowrepository.org/id/FR-FCM-Z2ZZ.

\section{Introduction}

Non-human primates (NHPs) are critical components of drug development because of their similarity to humans. Many key immunology assays, such as flow cytometry, Western blots, immunohistochemistry and immunofluorescence microscopy, make use of antibodies to demarcate specific cell types and quantify signaling moieties. Very few antibodies are raised against non-human primate antigens; instead, researchers typically use anti-human antibodies that are cross-reactive with the non-human primate species that they are studying. To help researchers find antibodies for NHP research, the National Institutes of Health supports a highly valuable database of the cross-reactivity of commercially available antibodies with 13 NHP species (http://www.nhpreagents.org). The database is derived from manufacturer and investigator reports, and typically provides a simple yes/no statement about whether a clone stains a species, with occasional comments about staining intensity or specificity. While an invaluable resource, the database is limited in its coverage. For example, prior to this study, only 28 CD markers had been evaluated in African green monkeys.

Additionally, with few exceptions, the database lacks information about the cell types bound by cross-reactive antibodies, and there are many known instances of antibody clones binding different cell types in different species. For example, granulocyte and monocyte marker expression is known to be substantially different in humans than in non-human primates. Anti-human CD33 clone
AC104.3E3 was reported in the NIH database and manufacturer's datasheet as cross-reactive with rhesus and cynomolgus macaques, but our lab and others determined that in those species, it prominently stains granulocytes $(1,2)$, while in humans it stains monocytes and classical dendritic cells. As another example, the Fcy receptor CD16 is found on granulocytes in humans and sooty mangabeys, but not in macaques or baboons $(3,4)$, which will likely confound animal studies evaluating therapeutic antibodies, which may bind, transduce signals through and mediate internalization via this Fcy receptor. Yet another example is CD56, which is expressed on monocytes in macaques (5), but is a canonical NK cell marker in humans. Thus, researchers must confirm that each clone they use is staining the cell population of interest through literature review or experimental verification.

Here we present an expansion of both the breadth and depth of primate cross-reactivity data. We screened 332 monoclonal antibodies in blood from two individuals of each of four NHP species: rhesus macaque (Macaca mulatta), cynomolgus macaque (Macaca fascicularis), African green monkey (Chlorcebus aethiops) and olive/ yellow baboon (Papio hamadryas anubis x Papio hamadryas cynocephalus hybrid); and found more than 120 clones that stained one or more populations in each species. Furthermore, we included counter-stain antibodies that allowed us to determine staining specificity in at least five major immune cell populations. Data from the NHPs were compared to the same screen ran in our laboratory on human blood. Finally, we used the results from this screen to create the first 

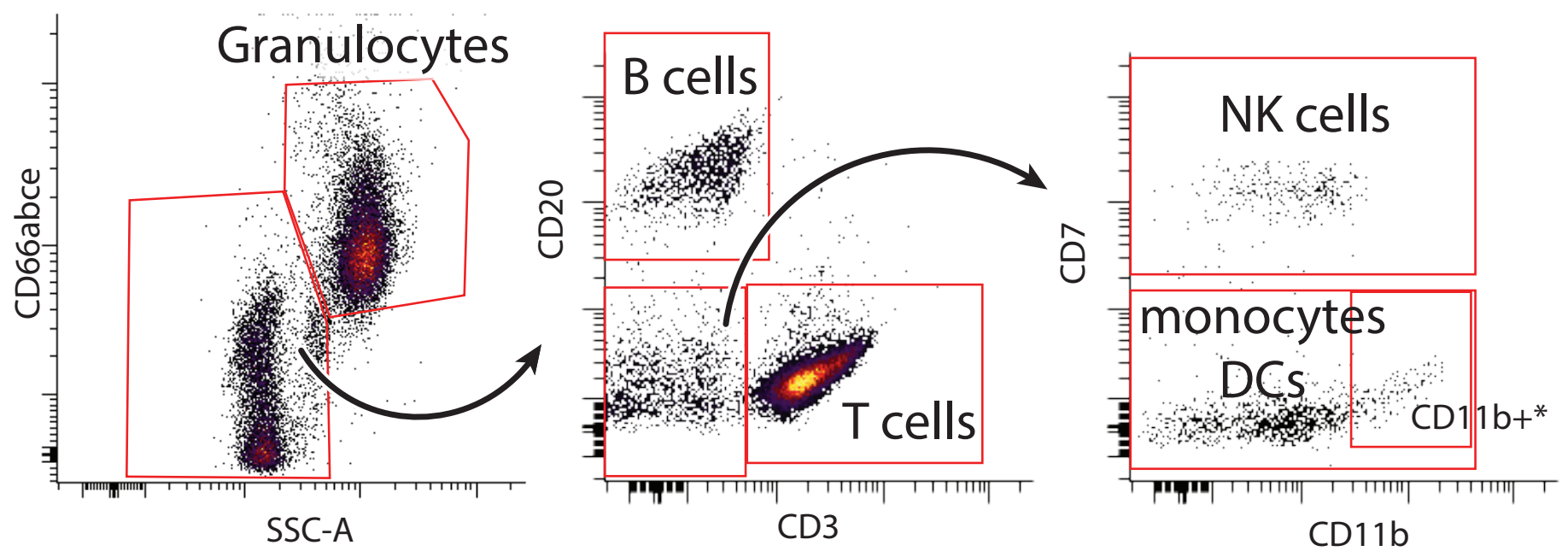

Figure 1. Five counterstains allow identification of at least five cell populations. Representative staining from a baboon shown. After gating by time to exclude artifacts, granulocytes were identified as CD66abce+/SSC-A+. Non-granulocytes were divided into B cells (CD20+/CD3-), $T$ cells (CD3+/CD20-), NK cells (CD7+/CD3-/CD20-) and monocytes/dendritic cells (CD7-/CD3-/CD20-). *In species other than the African green monkey, dendritic cells could be separated on the basis of CD11b staining.

mass cytometry phenotyping panels for African green monkeys and rhesus and cynomolgus macaques. These panels allow for effective side-by-side comparisons between non-human primate and human blood. All data is publicly accessible at https://immuneatlas.org and https://flowrepository.org/id/FR-FCM-Z2Z7.

\section{Results}

Counterstain panel and staining condition development

In order to identify the characteristics of these antigens across species, we first designed a panel of counterstain antibodies that delineate major circulating immune cell types in all five species (Figure 1). This panel readily identified granulocytes, $B$ cells, T cells, NK cells and monocytes/dendritic cells. In all species except for African green monkey, we could additionally separate the monocytes and dendritic cells based on CD11 b expression. In African green monkeys, CD11b (ICRF44) was non-reactive, and we chose not to include a substitute marker to maintain technical consistency across all species.

Additionally, we strategically selected the fluorophores to keep the PE channel, which was used for the screened antibody, free of bleed/compensation to avoid technical artifacts.

Fixation and red blood cell lysis conditions were selected after testing a large number of protocols on the basis of preserving antigen staining and effectively lysing non-human primate blood (data not shown). Fixation with approximately $0.3 \%$ PFA was low enough to avoid obvious loss of staining and sufficient to minimize morphological changes of cells as observed as forward and side scatter signals changing over the course of acquisition on the cytometer. Enzymatic lysis with VersaLyse was highly effective for both human and non-human primate blood, whereas other methods such as hypotonic lysis were inadequate or inconsistent for non-human primate blood.

\section{Antibody reactivity screen}

We established universal criteria for defining positive expression to determine antigen expression in an unbiased manner. An antibody clone was classified as reactive with a population if more than 10 percent of cells had a PE signal intensity greater than the 95th percentile of the intensity of the corresponding isotype control for the same species and population (Table I). This threshold was found to accurately reflect the results of manual classification: We verified 500 of the 14,940 clone $x$ species $x$ population results, taking into consideration reported staining patterns (references included $(2,5$, 7-13)) and the visual degree of separation from the isotype control, and calculated a false-positive rate of $7.4 \%$ and a false-negative rate of $1.6 \%$, for an initial accuracy of $91 \%$ in our data. Then, we manually verified and corrected as necessary all discordant replicates and all clones that were classified as reactive in a non-human primate species but not in a human; thus, our final estimated accuracy exceeds $91 \%$. All data from this project are publicly available, such that researchers can independently validate the expression of antigens of interest by accessing the primary data. In total, we identified 260, $153,129,161$ and 147 clones that are reactive with one or more populations in human, cynomolgus macaque, rhesus macaque, African green monkey and baboon, respectively.

Researchers interested in evaluating the antibodies in this study are directed to examine the primary data at https://immuneatlas.org or https://flowrepository.org/id/FR-FCM-Z2Z7, where one can compare the relative staining intensity and distribution of staining between species. Such review is critical when evaluating antibodies that stain rare populations-especially populations that comprise less than 10 percent of one of the populations that we delineated, or that show dim expression that might be excluded by the threshold for expression and staining that we applied. Additionally, we encourage diligence when interpreting markers such as CD41 and CD51/ CD61, which are listed as reactive with all cell types, but in actuality are probably staining platelet fragments stuck to other cells, based on the known distribution of those markers in humans (14). It is also important to keep in mind that actual antibody-antigen specificity may vary by species due to differences in gene sequence, protein structure and post-translational modifications.

\section{Notable examples of differences in expression patterns}

As noted above, in macaques CD33 is found on granulocytes and CD16 is restricted to monocytes and dendritic cells. In this study, we found that African green monkeys share this same staining pat- 
bioRxiv preprint doi: https://doi.org/10.1101/577759; this version posted March 14, 2019. The copyright holder for this preprint (which was not certified by peer review) is the author/funder. All rights reserved. No reuse allowed without permission.

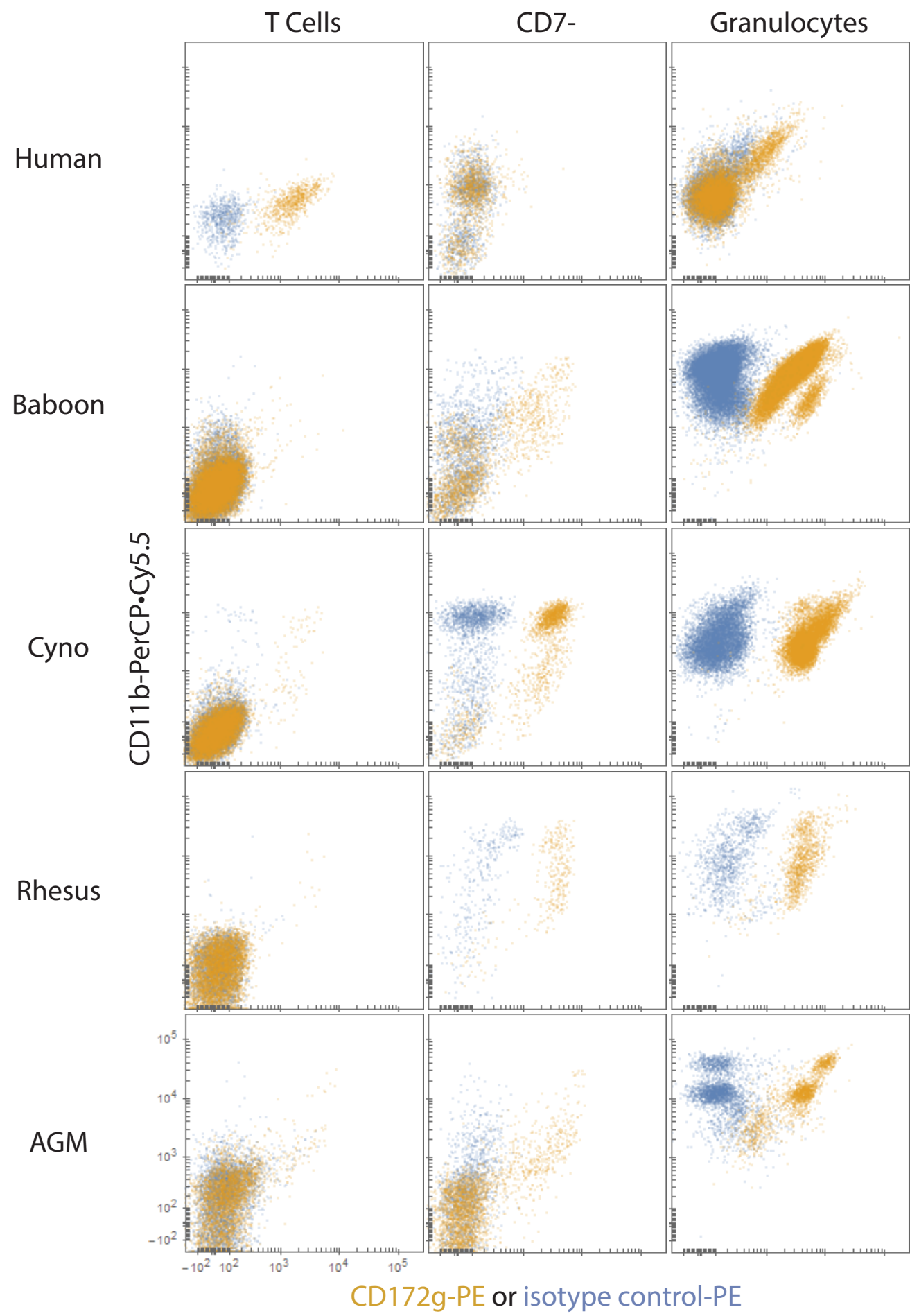

Figure 2. CD172g is expressed on monocytes and all granulocytes, but not on T cells, in examined NHP species. By comparison, CD172g is expressed on all T cells, a subset of granulocytes and a subset of B cells (data not shown) in humans. As discussed in the text, CD11b did not uniformly stain AGMs; thus, some of the CD11b-negative cells are monocytes. Blue: isotype control, orange: CD172g.

tern, albeit with weaker CD33 staining. Another notable difference (out of numerous idiosyncratic expression patterns observed) is that CD172g (signal regulatory protein (SIRP) $\gamma$, also known as SIRP $\beta 2$ ) is expressed on CD11b+ monocytes and granulocytes, but not on $\mathrm{T}$ cells, in all of the NHP species examined. In contrast, in humans this marker is expressed on T cells, some B cells and to some degree in granulocytes (Figure 2). Because it lacks a cytoplasmic signaling domain, CD172g is postulated to signal unidirectionally by activating the CD47-expressing cell and inducing $T$ cell migration and prolifer- ation in humans, mice and rats (15-17). Thus, our finding suggests a major difference in regulation of immune cell migration and adaptive response, which warrants further study.

Another notable example of the differences found is the presence of CD2 staining not only on T cells, but also on B cells in rhesus macaques, cynomolgus macaques, African green monkeys and to a slight extent baboons (Figure 3). CD2 is involved in adhesion, co-stimulation, antigen recognition and potentially differentiation $(18,19)$. In mice, virtually all circulating and bone marrow $B$ cells express CD2 

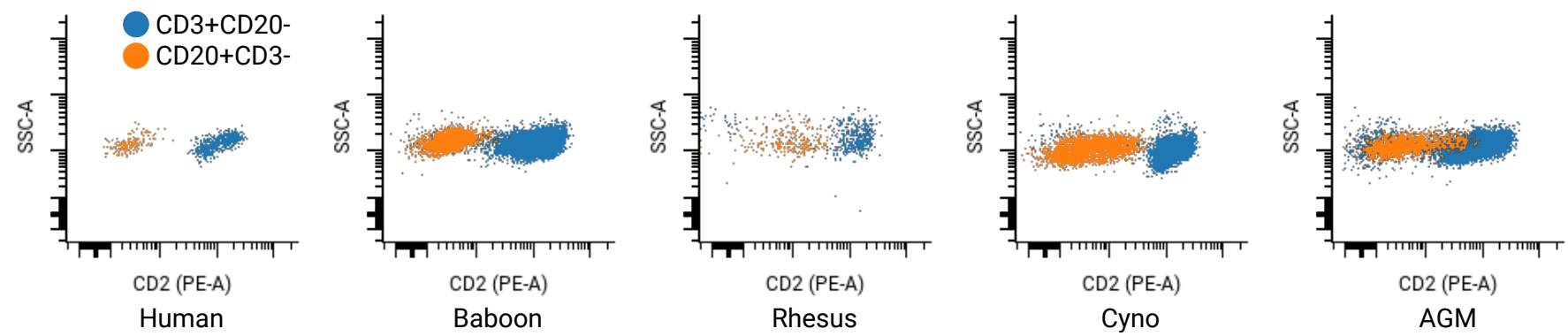

Figure 3. CD2 is expressed on B cells in NHPs. Blue: CD3+ T cells where expression is expected in humans; orange: CD20+ B cells.

(18). Kingma et al. previously reported that only a small subset (5.74 $+/-2.46 \%$ ) of normal human peripheral blood B cells express CD2, although approximately $25 \%$ of surveyed $B$ cell neoplasms expressed CD2 (20). We observed no CD2+ B cells in human. B cell CD2 expression thus seems to have been lost evolutionarily, with the most abundant expression in the oldest species (mouse), moderate expression in macaques and African greens, less expression in baboons and essentially no expression in the youngest species (human). Interestingly, the ligand is not conserved between species: CD2 exclusively binds CD48 in mice and rats, while in humans it strongly binds CD58 and only weakly binds CD48, which is also co-expressed with CD58 $(19,21)$.

\section{CyTOF panel design}

We used the results of the antibody screen, along with the results of several targeted follow-up experiments, to craft a set of parallel CyTOF mass cytometry panels for rhesus and cynomolgus macaque, African green monkey and human (Table II).

Wherever possible, we used the same antibody clones for all species. In the case of erythrocytes, we used the common marker CD235a for humans and CD233 for NHPs, instead of using the less common CD233 for all species (no anti-CD235 clone reactive with NHPs could be found). In the case of CD11C, clone 3.9 was only used in non-human primates because Bu15 was non-reactive, but 3.9 is reported to preferentially bind activated CD11C (22) and requires the addition of magnesium as a cofactor during staining $(22,23)$. We primarily use CD16 in lieu of CD11c during gating analysis for consistency. In the case of naïve and memory T cells, we observed very
Table II: CyTOF mass cytometry panels for orthologous phenotyping of humans and three species of NHPs. Canonical cell targets (rows) are listed along with mass channel, and antibody clones used for staining humans, macaques, and African green. Clones are listed in parentheses. * indicates weak staining.

\begin{tabular}{|c|c|c|c|c|}
\hline Canonical Target & Channel & Human & Macaque & African green \\
\hline Lymph/mono & 115 & CD45 (HI30) & CD45 (DO58-1283) & CD45 (DO58-1283) \\
\hline Erythrocytes & 113 & CD235a (HIR2) & CD233 (BRIC6) & \\
\hline Platelets & 140 & CD61 (VI-PL2) & CD61 (VI-PL2) & CD61 (VI-PL2) \\
\hline Granulocytes & 158 & CD66abce (TET2) & CD66abce (TET2) & CD66abce (TET2) \\
\hline Granulocytes & 142 & & CD33 (AC104.3E3) & CD33 (AC104.3E3)* \\
\hline B cells & 173 & $\mathrm{CD} 20(2 \mathrm{H} 7)$ & $\mathrm{CD} 20(2 \mathrm{H} 7)$ & $\mathrm{CD} 20(2 \mathrm{H} 7)$ \\
\hline B cells, class-switched & 174 & $\lg M(G 20-127)$ & $\lg M(G 20-127)$ & $\lg M(G 20-127)$ \\
\hline APCs $(B, D C)$ & 176 & HLA-DR (Immu357) & HLA-DR (Immu357) & HLA-DR (Immu357) \\
\hline DCs, B cells & 162 & CD1c (AD5-8E7) & CD1c (AD5-8E7) & CD1c (AD5-8E7) \\
\hline $\mathrm{cDCs}$ & 164 & BDCA3 (1A4) & BDCA3 (1A4) & BDCA3 (1A4) \\
\hline $\mathrm{pDCs}$ & 148 & CD123 (7G3) & CD123 (7G3) & CD123 (7G3) \\
\hline T cells & 157 & CD3 (SP34.2) & CD3 (SP34.2) & CD3 (SP34.2) \\
\hline CD4+ T cells & 156 & CD4 (OKT4) & CD4 (OKT4) & CD4 (L200) \\
\hline CD8+ $T$ cells & 155 & CD8a (RPA-T8) & CD8a (RPA-T8) & CD8a (RPA-T8) \\
\hline Naïve T cells & 166 & CD45RA (HI100) & CD45RA (HI100) & \\
\hline Myeloid cells & 153 & CD11b (ICRF44) & CD11b (ICRF44) & CD11b (ICRF44) \\
\hline Myeloid, T subset & 143 & CD11c (Bu15) & CD11c (3.9) & CD11c (3.9) \\
\hline Monocytes & 151 & CD14 (M5E2) & CD14 (M5E2) & CD14 (M5E2) \\
\hline NK, mono, gran & 159 & CD16 (3G8) & CD16 (3G8) & CD16 (3G8) \\
\hline Myeloid & 142 & CD33 (AC104.3E3) & & \\
\hline Monocytes & 175 & & CD56 (NCAM16.2) & \\
\hline NK cells & 175 & CD56 (NCAM16.2) & & \\
\hline NK cells & 141 & CD7 (M-T701) & CD7 (M-T701) & CD7 (M-T701) \\
\hline NK cells & 168 & CD161 (HP-G310) & CD161 (HP-G310) & CD161 (HP-G310) \\
\hline
\end{tabular}


bioRxiv preprint doi: https://doi.org/10.1101/577759; this version posted March 14,2019 . The copyright holder for this preprint (which was not certified by peer review) is the author/funder. All rights reserved. No reuse allowed without permission.

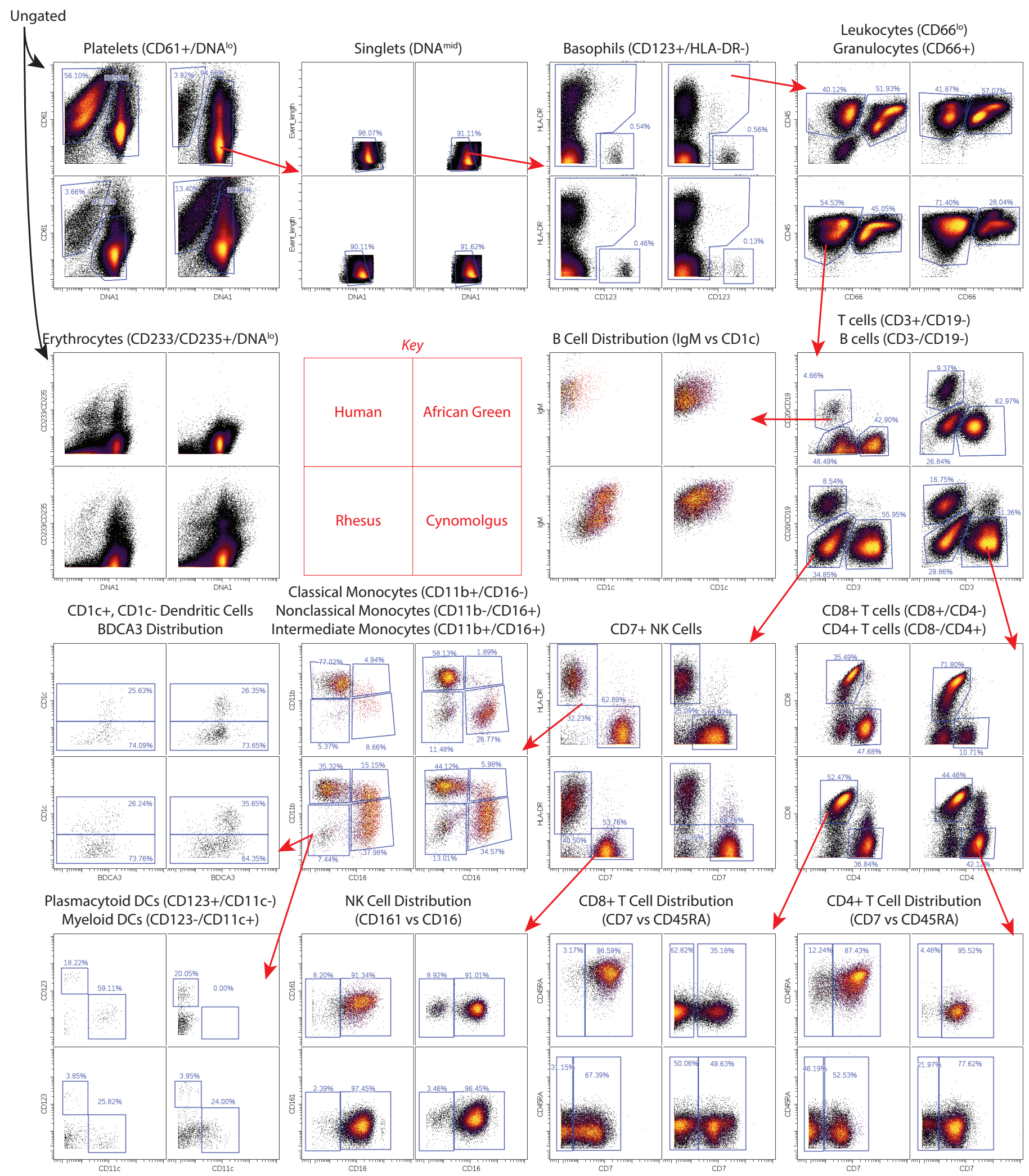

Figure 4: Parallel gating of blood from four species. CyTOF mass cytometry panels were developed to delineate at least 18 orthologous populations between species. 
broad distribution of CD45RA staining, as previously reported (24, 25), with two clones (5H9 and HI100), which was difficult to gate (see online dataset). Staining of this marker was superior with the VersaLyse-based method than with the Triton-X100-based method (see methods) (data not shown).

The experiments described here are especially valuable for the advancement of African green monkey (AGM) immunology because there is a dearth of literature discussing immunophenotyping and only 28 reactive antibodies listed in the $\mathrm{NIH}$ database. Nonetheless, this species is important in drug development-especially SIV research-and is the subject of an international effort to make it the most comprehensively characterized NHP by phenotype and genomics (26). Notably, the usage of AGMs is increasing due to a shortage of rhesus macaques for research (27). It was generally possible to use the same clones for African green monkeys as we were for macaques, with several exceptions (Table II). No reactive clones were found for CD11c; instead, we again rely on CD16 for gating monocyte subpopulations and CD123, CD1C and BDCA3 for gating dendritic cell subpopulations.

These CyTOF panels were exhaustively titrated to determine optimal staining concentrations for each antibody, then revalidated in at least two donors from each species. We subsequently contracted BioLyph LLC to lyophilize and package several thousand single-use pellets ("LyoSpheres") of each of these panels for use in later studies. These pellets solve stability issues such as evaporation and precipitation that inhibit long-term studies and eliminate the technical variability and errors that arise from pipetting. As such, these panels allow for parallel evaluation of orthologous populations between species (Figure 4).

\section{Discussion}

We have substantially expanded the breadth and depth of available antibody cross-reactivity data between primate species, and have deposited the dataset containing the primary flow cytometry data online so that any user can easily compare staining patterns in these species, and even look at subpopulations of cells to check specificity-information not typically reported in the NIH database.

As a result of evaluating specific cell types, we have identified numerous antibodies that stain different populations in non-human primates than in humans. In light of this, researchers must take adequate steps to ensure they are evaluating the intended populations when using these reagents, and when evaluating immunotherapeutics targeting these proteins.

While we screened 332 different anti-human antibody clones, not all of the antigens targeted by those antibodies are expected to be present in the resting, peripheral blood cells that we tested. Indeed, only $78.3 \%$ (260/332) of the antibodies positively stained human blood. Thus, our screen did not evaluate markers that are found only in cells from bone marrow and other tissues, in progenitors or in activated populations. However, blood is the most easily accessed and likely the most common biological sample type used in research environments, and we thus expect this knowledge about blood to be of the greatest use to most researchers. We hope that the framework we have developed will be expanded upon with additional clones and/or additional species in future studies.

Finally, we present the first CyTOF mass cytometry panels for coordinated human and non-human primate research. We have continued to use these panels for large-scale comparisons of primate immune systems (in review).

\section{Materials and Methods}

Blood

Macaque blood was obtained from Valley Biosystems, Inc. (location withheld). African green monkey blood was obtained from Bioreclamation, LLC (Westbury, NY) and Worldwide Primates, Inc. (location withheld). Baboon blood was obtained from the Southwest National Primate Research Center, which is funded by the National Center for Research Resources (p51 RR013986) and supported by the Office of Research Infrastructure Programs/OD P51 OD011133. All animal blood was collected under an approved animal care and use protocol. Human blood was obtained from a healthy adult donor under an approved IRB protocol.

\section{Antibody screen}

Blood was collected in sodium heparin and processed within 24 hours of collection. Eight to $10 \mathrm{ml}$ of blood was gently fixed and lysed by incubating with $792 \mu \mathrm{l}$ of $16 \%$ paraformaldehyde (Electron Microscopy Sciences, Hatfield, PA; final concentration approx. 0.3\%) and $29.6 \mathrm{ml}$ of VersaLyse (Beckman Coulter, Brea, CA) for 10 minutes at room temperature, then washed once with $0.01 \%$ BSA in PBS ("staining buffer"). Cells were resuspended in $6.5 \mathrm{ml}$ of staining buffer, then incubated with $0.5 \mathrm{ml}$ of human TruStain FcX Fc receptor blocking solution (Biolegend, San Diego, CA) for 10 minutes.

Five counterstain antibodies were then added: $500 \mu \mathrm{l} C D 3$ (SP34.2)-Brilliant Violet 421 (BD Biosciences, San Jose, CA), $500 \mu \mathrm{l}$ CD20 (2H7)-Brilliant Violet 605 (Biolegend), $1000 \mu \mathrm{l} \mathrm{CD66} \mathrm{(TET2)-}$ APC-Vio770 (Miltenyi, San Diego, CA), $500 \mu \mathrm{l} \mathrm{CD11b}$ (ICRF44)-PerCP/ Cy5.5 (Biolegend) and $500 \mu \mathrm{lCD} 7$ (M-T701)-APC (BD Biosciences), for a final volume of $10 \mathrm{ml}$.

Subsequent steps were performed on an automation platform including an Agilent Bravo 96-channel pipetting robot, centrifuges, BioTek ELx405 96-channel aspirator/dispenser and Thermo Scientific MultiDrop dispenser. Twenty microliters of cells in the antibody cocktail were dispensed into every well of a 384-well plate using the MultiDrop. LegendScreen Human PE antibody screen plates (Biolegend) were rehydrated with the manufacturer-recommended $25 \mu$ of water. The screen consists of four 96-well plates; $5 \mu \mathrm{l}$ from each well were transferred to the single 384-well plate quadrant-wise. Staining reactions were incubated in the dark at room temperature for 30 minutes with $2.0 \mathrm{~mm}$-radius orbital shaking, then washed three times with staining buffer and acquired on a BD LSR II with 405, 488 and $633 \mathrm{~nm}$ lasers using an HTS autosampler.

Files were gated and populations exported using a webbased, high-throughput cytometry analysis platform developed in our laboratory. Every well was manually gated by time to exclude anomalies caused by air bubbles or debris: temporal regions where the signal in the PE channel over time were inconsistent were excluded. Cell populations were then gated as described in the results section. Population gates were tailored to each species; tailoring to individual donors within a species was not necessary. The remaining analysis (statistics calculations, discordant replicate resolution, verification and reporting) was performed using Mathematica (Wolfram Research, Champaign, IL).

\section{CyTOF mass cytometry}

Purified antibodies (BioLegend, BD, Beckman Coulter) were conjugated to stable metal isotopes using commercially available polymeric chelators ("X8," Fluidigim, Markham, Ontario, Canada). 
Whole blood was lysed and prepared using the method of Chow and Hedley (6), which is better suited to high-throughput, plate-based assays than the Versalyse method described earlier. Briefly, we mixed $330 \mu \mathrm{l}$ of blood with $55 \mu \mathrm{l}$ of $16 \%$ PFA, incubated for 10 minutes, then added $1,615 \mu$ of $0.127 \%$ Triton-X100 (Fisher Scientific, Waltham, $\mathrm{MA}$ ) in PBS (final concentration of $0.1 \%$ Triton) and incubated for 30 minutes. We then washed, stained with the metal-tagged antibodies for 30 minutes and washed again. Cells were subjected to a second fixation with $1.5 \%$ paraformaldehyde and DNA staining with iridium intercalator (Fluidigm), then acquired on a CyTOF 2 mass cytometer (Fluidigm).

\section{Disclaimer and Acknowledgements}

The research discussed in this article was supported in part by the U.S. Food and Drug Administration (Contract No. HHSF223201210194C). Additional support was provided by $\mathrm{NIH}$ awards 5R01CA18496804, 5R25CA18099304, 1R01GM10983604, 5UH2AR06767603, 1R01NS08953304 and R01HL120724, and FDA contract HHSF223201610018C. Z.B.B.H. was supported in part by NIH grant T32GM007276. G.K.F. was supported in part by a Stanford Bio-X graduate research fellowship and NIH grant T32GM007276. M.H.S. was supported in part by NIH grant DP5OD023056. This article reflects the views of the authors and should not be construed to represent the U.S. Food and Drug Administration or NIH's views or policies.

Thanks goes to BioLegend Inc. for providing the screening plates, and to the NIH Nonhuman Primate Reagent Resource (R24 RR016001 and NIAID contract HHSN 2722000900037C).

Author contributions: Z.B.B.H. generated the data, performed the analysis and wrote the manuscript. G.K.F. and M.H.S. contributed to panel design and edited the manuscript. K.H. contributed to data generation. D.M. contributed to data generation and reagent optimization. K.L. edited the manuscript and advised analysis. G.P.N. advised the study and edited the manuscript.

Declaration of interests: Z.B.B.H. is involved in the commercial development of the platform used to host the data presented here, although the data presented here will always be freely accessible.

\section{References}

1. Uchida, N., P. W. Hargrove, C. J. Lap, M. E. Evans, O. Phang, A. C. Bonifacino, A. E. Krouse, M. E. Metzger, A.-D. Nguyen, M. M. Hsieh, T. G. Wolfsberg, R. E. Donahue, D. a. Persons, and J. F. Tisdale. 2012. High-efficiency Transduction of Rhesus Hematopoietic Repopulating Cells by a Modified HIV1based Lentiviral Vector. Mol. Ther. 20: 1882-1892.

2. Brown, K. N., and S. M. Barratt-Boyes. 2009. Surface phenotype and rapid quantification of blood dendritic cell subsets in the rhesus macaque. J. Med. Primatol. 38: 272-8.

3. Rogers, K. A., F. Scinicariello, and R. Attanasio. 2006. IgG Fc receptor III homologues in nonhuman primate species: genetic characterization and ligand interactions. J. Immunol. 177: 3848-56.

4. Rogers, K. A., F. Scinicariello, and R. Attanasio. 2004. Identification and characterization of macaque CD89 (immunoglobulin A Fc receptor). Immunology 113: 178-86.

5. Carter, D. L., T. M. Shieh, R. L. Blosser, K. R. Chadwick, J. B. Margolick, J. E. K. Hildreth, J. E. Clements, and M. C. Zink. 1999. CD56 identifies monocytes and not natural killer cells in rhesus macaques. Cytometry 37: 41-50.

6. Chow, S., D. Hedley, P. Grom, R. Magari, J. W. Jacobberger, and T. V. Shankey. 2005. Whole blood fixation and permeabilization protocol with red blood cell lysis for flow cytometry of intracellular phosphorylated epitopes in leukocyte subpopulations. Cytom. Part A 67: 4-17.

7. Autissier, P., C. Soulas, T. H. Burdo, and K. C. Williams. 2010. Immunophenotyping of lymphocyte, monocyte and dendritic cell subsets in normal rhesus macaques by 12 -color flow cytometry: clarification on DC heterogeneity. J. Immunol. Methods 360: 119-28.
8. Autissier, P., C. Soulas, T. H. Burdo, and K. C. Williams. 2010. Evaluation of a 12-color flow cytometry panel to study lymphocyte, monocyte, and dendritic cell subsets in humans. Cytometry. A 77: 410-9.

9. Coates, P. T. H., S. M. Barratt-Boyes, L. Zhang, V. S. Donnenberg, P. J. O'Connell, A. J. Logar, F. J. Duncan, M. Murphey-Corb, A. D. Donnenberg, A. E. Morelli, C. R. Maliszewski, and A. W. Thomson. 2003. Dendritic cell subsets in blood and lymphoid tissue of rhesus monkeys and their mobilization with Flt3 ligand. Blood 102: 2513-21.

10. Jesudason, S., M. G. Collins, N. M. Rogers, S. Kireta, and P. T. H. Coates. 2012. Non-human primate dendritic cells. J. Leukoc. Biol. 91: 217-228.

11. Reimann, K. a, B. C. Waite, D. E. Lee-Parritz, W. Lin, B. Uchanska-Ziegler, M. J. O'Connell, and N. L. Letvin. 1994. Use of human leukocyte-specific monoclonal antibodies for clinically immunophenotyping lymphocytes of rhesus monkeys. Cytometry 17: 102-108.

12. Sopper, S., C. Stahl-Hennig, M. Demuth, I. C. Johnston, R. Dörries, and V. ter Meulen. 1997. Lymphocyte subsets and expression of differentiation markers in blood and lymphoid organs of rhesus monkeys. Cytometry 29: 351-62.

13. Webster, R. L., and R. P. Johnson. 2005. Delineation of multiple subpopulations of natural killer cells in rhesus macaques. Immunology 115 : 206-214.

14. Nurden, A. T., J. N. George, and D. R. Phillips. 1986. Platelet Membrane Glycoproteins: Their Structure, Function, and Modification in Disease. In Biochemistry of Platelets D. Phillips, and M. A. Shuman, eds. Academic Press Inc. 160-212.

15. Brooke, G., J. D. Holbrook, M. H. Brown, and A. N. Barclay. 2004. Human lymphocytes interact directly with CD47 through a novel member of the signal regulatory protein (SIRP) family. J. Immunol. 173: 2562-70.

16. Barclay, A. N., and M. H. Brown. 2006. The SIRP family of receptors and immune regulation. Nat. Rev. Immunol. 6: 457-64.

17. Piccio, L., W. Vermi, K. S. Boles, A. Fuchs, C. A. Strader, F. Facchetti, M. Cella, and M. Colonna. 2005. Adhesion of human T cells to antigen-presenting cells through SIRPbeta2-CD47 interaction costimulates T-cell proliferation. Blood 105: 2421-7.

18. Yagita, H., T. Nakamura, J. Asakawa, H. Matsuda, S. Tansyo, Y. ligo, and K. Okumura. 1989. CD2 expression in murine B cell lineage. Int. Immunol. 1:94-8.

19. Davis, S. J., and P. A. van der Merwe. 1996. The structure and ligand interactions of CD2: implications for T-cell function. Immunol. Today 17: 177-187.

20. Kingma, D. W., P. Imus, X. Y. Xie, G. Jasper, L. Sorbara, C. Stewart, and M. Stetler-Stevenson. 2002. CD2 is expressed by a subpopulation of normal $B$ cells and is frequently present in mature B-cell neoplasms. Cytometry 50: 243-8.

21. Davis, S. J., S. Ikemizu, M. K. Wild, and P. A. Merwe. 1998. CD2 and the nature of protein interactions mediating cell-cell recognition. Immunol. Rev. 163: 217-236.

22. Sadhu, C., L. Hendrickson, K. O. Dick, T. G. Potter, and D. E. Staunton. 2008. Novel tools for functional analysis of CD11c: activation-specific, activation-independent, and activating antibodies. J. Immunoassay Immunochem. 29: 42-57.

23. Ihanus E., Uotila L. M., Toivanen A., Varis M., G. C. G. 2007. Red-cell ICAM-4 is a ligand for the monocyte-macrophage integrin CD11C/CD18: characterization of the binding sites on ICAM-4. Blood 802-810.

24. Valentine, M., K. Song, G. A. Maresh, H. Mack, M. C. Huaman, P. Polacino, O. Ho, A. Cristillo, H. Kyung Chung, S.-L. Hu, and S. H. Pincus. 2013. Expression of the memory marker CD45RO on helper T cells in macaques. PLoS One 8: e73969.

25. Pitcher, C. J., S. I. Hagen, J. M. Walker, R. Lum, B. L. Mitchell, V. C. Maino, M. K. Axthelm, and L. J. Picker. 2002. Development and Homeostasis of T Cell Memory in Rhesus Macaque. J. Immunol. 168: 29-43.

26. Jasinska, A. J., C. A. Schmitt, S. K. Service, R. M. Cantor, K. Dewar, J. D. Jentsch, J. R. Kaplan, T. R. Turner, W. C. Warren, G. M. Weinstock, R. P. Woods, and N. B. Freimer. 2013. Systems biology of the vervet monkey. ILAR J. 54: 122-43.

27. Cohen, J. 2000. AIDS RESEARCH:Vaccine Studies Stymied by Shortage of Animals. Science (80-. ). 287: 959-960. 
bioRxiv preprint doi: https://doi.org/10.1101/577759; this version posted March 14,2019 . The copyright holder for this preprint (which was not certified by peer review) is the author/funder. All rights reserved. No reuse allowed without permission.

Table I: Summary of cell type-specific cross-reactivity. Clones were considered reactive if at least 10 percent of cells had a signal greater than the signal of the 95th percentile of corresponding isotype control or if they were manually classified as positive. Presence of letter in column indicates reactive staining detected in that cell population, absence of letter indicates clone is unreactive in that cell population. B: B cells, $\mathrm{T}$ : $\mathrm{T}$ cells, N: CD7+ NK cells, M: CD7- monocytes and dendritic cells, G: granulocytes, ?: inconclusive, insufficient number of cells acquired for a given population to make clear assessment. Two of each non-human primate species and one human were assayed.

\begin{tabular}{|c|c|c|c|c|c|c|}
\hline Antibody & Clone & Human & Cyno & Rhesus & Baboon & AGM \\
\hline CD1a & HI149 & $T \quad G$ & & & & \\
\hline CD1b & SN13 (K5-1B8) & $T \quad G$ & $M$ & & & $T \quad G$ \\
\hline CD1c & L161 & B $M$ & B $\quad M$ & B $M$ & B $M$ & $B$ \\
\hline CD1d & 51.1 & B $M$ & & & & \\
\hline CD2 & RPA-2.10 & $\mathrm{TN}$ & BTN & BTN & BTNM & BTN \\
\hline CD3 & HIT3a & $\mathrm{T}$ & & & & \\
\hline CD4 & RPA-T4 & T M & $\mathrm{T}$ & & & \\
\hline CD5 & UCHT2 & BT $\quad$ G & & & & \\
\hline CD6 & BL-CD6 & BTN G & & & & \\
\hline CD7 & CD7-6B7 & TN & & & & \\
\hline CD8a & HIT8a & TN & & & & \\
\hline CD9 & $\mathrm{HI} 9 \mathrm{a}$ & ?T?MG & BTNMG & BTNMG & BTNMG & BTNMG \\
\hline CD10 & HI10a & BTN G & MG & $G$ & MG & $\mathrm{G}$ \\
\hline CD11a & HI111 & BTNMG & M & & & \\
\hline CD11b & CBRM $1 / 5$ & BT $\quad G$ & & & & \\
\hline CD11b & ICRF44 & BTNMG & B NMG & BTNMG & B NMG & BTNMG \\
\hline CD11c & 3.9 & B $\quad$ MG & B $\quad$ M & B & B $M$ & \\
\hline CD13 & WM15 & T MG & & & & T MG \\
\hline CD14 & M5E2 & BT MG & MG & MG & & $\mathrm{G}$ \\
\hline CD15 & W6D3 & MG & & & & \\
\hline CD16 & $3 \mathrm{G} 8$ & BTNMG & TNM & TNM & TNM & $\mathrm{N}$ \\
\hline CD18 & TS1/18 & BTNMG & & & & \\
\hline CD19 & HIB19 & $B$ & & B & & \\
\hline CD20 & $2 \mathrm{H} 7$ & $B$ & $B$ & $B$ & B N & $B$ \\
\hline CD21 & Bu32 & BT & B & & B & $B$ \\
\hline CD22 & HIB22 & $B$ & & & & \\
\hline CD23 & EBVCS-5 & ????? & & & & \\
\hline CD24 & ML5 & BTNMG & & & & \\
\hline CD25 & BC96 & BTN & & & $T$ & \\
\hline CD26 & BA5b & TN & & & & \\
\hline CD27 & 0323 & BTN & BTN & BTN & BTNM & BTN \\
\hline CD28 & CD28.2 & TN & $\mathrm{T}$ & $T$ & $T$ & $T$ \\
\hline CD29 & TS2/16 & BTNMG & BTNMG & BTNMG & BTNMG & BTNMG \\
\hline CD30 & BY88 & & & & & \\
\hline CD31 & WM59 & BTNMG & BTNMG & BTNMG & BTNMG & BTNMG \\
\hline CD32 & FUN-2 & BTNMG & BT MG & BTNMG & BTNMG & B $\quad M G$ \\
\hline CD33 & WM53 & NMG & & & & \\
\hline CD34 & 581 & & & & & \\
\hline CD35 & E11 & ????? & BT MG & BT MG & BT MG & $B \quad G$ \\
\hline CD36 & $5-271$ & BTNMG & & & & \\
\hline CD38 & HIT2 & BTNMG & & & & \\
\hline CD39 & A1 & BTNMG & BTNMG & MG & BTNMG & B $\quad M G$ \\
\hline CD40 & HB14 & B $M$ & B $\quad M$ & B & B & B $\quad M$ \\
\hline CD41 & HIP8 & BTNMG & BTNMG & BTNMG & BTNMG & BTNMG \\
\hline CD42b & HIP1 & BTNMG & & & & \\
\hline CD43 & CD43-10G7 & BT?MG & $\mathrm{T} \quad \mathrm{G}$ & & $T$ & T MG \\
\hline CD44 & BJ18 & BTNMG & BTNMG & BTNMG & BTNMG & BTN $G$ \\
\hline CD45 & $\mathrm{HI} 3 \mathrm{O}_{\mathrm{O}}$ & BT?MG & & & & \\
\hline CD45RA & HI100 & BT?M & & & & \\
\hline CD45RB & MEM-55 & BTNM & BTNMG & BTNM & BTNM & BTN \\
\hline CD45RO & UCHL1 & ????? & & & & \\
\hline CD46 & TRA-2-10 & BTNMG & & & & \\
\hline CD47 & $\mathrm{CC} 2 \mathrm{C} 6$ & BTNMG & BTNMG & BTNMG & BTNMG & BTNMG \\
\hline CD48 & BJ40 & BTNMG & $\begin{array}{ll}B & M \\
\end{array}$ & B $\quad$ MG & B $\quad$ MG & BTNMG \\
\hline CD49a & TS2/7 & TNM & $\mathrm{TN}$ & $T$ & $\begin{array}{ll}T \\
\end{array}$ & TN \\
\hline CD49c & ASC-1 & BTN & & & & \\
\hline CD49d & 9F10 & BTNMG & BTNMG & BTNMG & BTNMG & BTNMG \\
\hline CD49e & NKI-SAM-1 & TNMG & TNMG & TNMG & BTNMG & BTNMG \\
\hline CD49f & GoH3 & BTNMG & BTNMG & BTNMG & BTNMG & BTNMG \\
\hline CD50 & CBR-IC3/1 & BTNMG & TNM & & TNMG & \\
\hline CD51 & NKI-M9 & & & & & \\
\hline CD51,CD61 & $23 \mathrm{C} 6$ & B $M$ & $T$ & & & $M$ \\
\hline CD52 & HI186 & BTNMG & $M$ & M & & \\
\hline CD53 & HI29 & BTNMG & & & & \\
\hline CD54 & HA58 & BTNMG & & & & \\
\hline CD55 & JS11 & BTNMG & $\mathrm{G}$ & & $\mathrm{G}$ & $\mathrm{G}$ \\
\hline CD56 & HCD56 & $\mathrm{N}$ & NM & NM & NM & $\mathrm{N}$ \\
\hline
\end{tabular}

\begin{tabular}{|c|c|c|c|c|c|c|}
\hline Antibody & Clone & Human & Cyno & Rhesus & Baboon & AGM \\
\hline CD57 & HCD57 & $\mathrm{N}$ & & & & \\
\hline CD58 & TS2/9 & BTNMG & BTNMG & BTNMG & BTNMG & BTNMG \\
\hline CD59 & p282 (H19) & BTNMG & BTNMG & BTNMG & BTNMG & \\
\hline CD61 & VI-PL2 & BTNMG & BTNMG & BTNMG & BTNMG & BTNMG \\
\hline CD62E & HAE-1f & & & & & \\
\hline CD62L & DREG-56 & BTNMG & & & & \\
\hline CD62P & AK4 & & & & & \\
\hline CD63 & $\mathrm{H} 5 \mathrm{C} 6$ & BTNMG & BTNMG & BTNMG & BTNMG & BTNMG \\
\hline CD64 & 10.1 & MG & MG & NMG & MG & $M G$ \\
\hline CD66a/b/c/e & TET2* & G & G & G & $\mathrm{G}$ & G \\
\hline CD66a/c/e & ASL-32 & G & & & & \\
\hline CD66b & G10F5 & G & & & & \\
\hline CD69 & FN50 & TNM & TN & $\mathrm{TN}$ & $G$ & B N \\
\hline CD70 & 113-16 & $\mathrm{T}$ & & & & \\
\hline CD71 & CY1G4 & BTNM & & & & \\
\hline CD73 & AD2 & BT G & & & $\mathrm{TN}$ & TN G \\
\hline CD74 & LN2 & BT MG & B $M$ & B $\quad$ MG & B $M$ & BT MG \\
\hline CD79b & CB3-1 & BTNMG & T $\quad G$ & G & T $\quad G$ & T M \\
\hline CD80 & 2D10 & BTN & & & & \\
\hline CD81 & $5 A 6$ & BTNMG & T M & BT M & BT MG & BTNMG \\
\hline CD82 & ASL-24 & BTNMG & $T \quad G$ & & $\mathrm{~T} \quad \mathrm{G}$ & $T \quad G$ \\
\hline CD83 & HB15e & $\begin{array}{ll}T \\
\end{array}$ & & $\mathrm{~T}$ & BT M & BT \\
\hline CD84 & CD84.1.21 & BTNMG & BTNMG & BTNMG & BTNMG & BTNMG \\
\hline CD85 & 17G10.2 & & & & & \\
\hline CD85 & GHI/75 & BTNMG & & & & \\
\hline CD85 & MKT5.1 & T MG & MG & MG & $\mathrm{G}$ & $\mathrm{G}$ \\
\hline CD85d & 42D1 & T MG & & & & \\
\hline CD85h & 24 & MG & & G & & \\
\hline CD85k & ZM4.1 & M & & & & \\
\hline CD86 & IT2.2 & BT MG & B $M$ & B $\quad$ MG & BT MG & BT MG \\
\hline CD87 & VIM5 & T MG & MG & BTNMG & MG & NMG \\
\hline CD88 & S5/1 & BTNMG & & & $G$ & $\mathrm{~T}$ \\
\hline CD89 & A59 & NMG & NMG & NMG & MG & $T \quad G$ \\
\hline CD90 & 5E10 & & BTNMG & BTNMG & BTNMG & BTNMG \\
\hline CD93 & VIMD2 & M & MG & MG & TNMG & TNMG \\
\hline CD94 & DX22 & TN & $\mathrm{T} \quad \mathrm{G}$ & & $\mathrm{T}$ & $\mathrm{T}$ \\
\hline CD95 & DX2 & BTNMG & BTNMG & BTNMG & BTNMG & BTNMG \\
\hline CD96 & NK92.39 & TN G & & & & \\
\hline CD97 & VIM3b & BTNMG & & $B$ & & \\
\hline CD99 & HCD99 & BT?MG & TN & & $T$ & T MG \\
\hline CD100 & A8 & BTNMG & BTNM & BTNM & BTNMG & BTNM \\
\hline CD101 & BB27 & BT MG & T MG & BTNMG & T MG & MG \\
\hline CD102 & CBR-IC2/2 & BTNMG & BTNMG & BTNM & BTNM & BTNMG \\
\hline CD103 & Ber-ACT8 & & & & & \\
\hline CD104 & 58XB4 & & & & & \\
\hline CD105 & $43 \mathrm{~A} 3$ & NM & & & & \\
\hline CD106 & STA & & & & & \\
\hline CD107a & $\mathrm{H} 4 \mathrm{~A} 3$ & BTNMG & T G & BTN & BT MG & BTNMG \\
\hline CD108 & MEM-150 & B NM & $B$ & $B$ & $B$ & $B$ \\
\hline CD109 & W7C5 & TNM & NM & & & $\mathrm{TN}$ \\
\hline CD111 & R1.302 & $\mathrm{N}$ & & & & \\
\hline CD112 & TX31 & T MG & & & & \\
\hline CD114 & LMM741 & NMG & G & & & \\
\hline CD115 & 9-4D2-1E4 & G & G & TN G & M & $\mathrm{T} \quad \mathrm{G}$ \\
\hline CD116 & $4 \mathrm{H} 1$ & T MG & & & & $T$ \\
\hline CD117 & 104D2 & $\mathrm{N}$ & & & & \\
\hline CD119 & GIR-208 & BTNMG & BTNMG & BTNMG & BTNMG & BTNMG \\
\hline CD122 & TU27 & TN & $\mathrm{N}$ & $\mathrm{N}$ & $\mathrm{N}$ & $\mathrm{N}$ \\
\hline CD123 & $6 \mathrm{H} 6$ & B NM & & & & \\
\hline CD124 & G077F6 & $B$ & & & & \\
\hline CD126 & UV4 & TNMG & T M & $T$ & $\mathrm{~T}$ & $T$ \\
\hline CD127 & A019D5 & TN & $T$ & $T$ & $\mathrm{TN}$ & $T$ \\
\hline CD129 & AH9R7 & TN & & TN & & $\begin{array}{ll}T & G \\
\end{array}$ \\
\hline CD131 & $1 \mathrm{C} 1$ & MG & MG & MG & MG & $\mathrm{G}$ \\
\hline CD132 & TUGh4 & BTNMG & MG & G & & T MG \\
\hline CD134 & $\begin{array}{l}\text { Ber-ACT35 } \\
\text { (ACT35) }\end{array}$ & $T$ & & & & \\
\hline
\end{tabular}


bioRxiv preprint doi: https://doi.org/10.1101/577759; this version posted March 14,2019 . The copyright holder for this preprint (which was not certified by peer review) is the author/funder. All rights reserved. No reuse allowed without permission.

\begin{tabular}{|c|c|c|c|c|c|c|}
\hline Antibody & Clone & Human & Cyno & Rhesus & Baboon & AGM \\
\hline CD135 & BV10A4H2 & & & & & \\
\hline CD137 & 4B4-1 & & & & & \\
\hline CD138 & DL-101 & TNMG & $T \quad G$ & & T MG & $T \quad G$ \\
\hline CD140a & 16A1 & & & & & \\
\hline CD140b & $18 \mathrm{~A} 2$ & G & $G$ & & $\mathrm{~T} \quad \mathrm{G}$ & $T \quad G$ \\
\hline CD141 & M80 & MG & & & $M$ & $M G$ \\
\hline CD143 & $5-369$ & T $\quad G$ & & & & \\
\hline CD144 & BV9 & & & & & \\
\hline CD146 & SHM- 57 & BTNMG & MG & & BTNMG & T MG \\
\hline CD148 & A3 & BTNMG & & & & \\
\hline CD150 & A12 (7D4) & BT & BT & BT & BT & BT \\
\hline CD152 & L3D10 & & & & & \\
\hline CD154 & $24-31$ & BTNMG & & & & \\
\hline CD155 & SKII.4 & NMG & & & & \\
\hline CD156c & SHM14 & BTNMG & BTNMG & BTNMG & BTNMG & BTNMG \\
\hline CD158a/h & HP-MA4 & $\mathrm{N}$ & $\mathrm{N}$ & & $\mathrm{NG}$ & \\
\hline CD158b & DX27 & $\mathrm{N}$ & & & & \\
\hline CD158d & mAb 33 (33) & TN G & & & & \\
\hline CD158e1 & DX9 & $\mathrm{N}$ & & & & \\
\hline CD158f & UP-R1 & T MG & & & & \\
\hline CD161 & HP-3G10 & TNMG & TN & TNM & TNMG & $\mathrm{N}$ \\
\hline CD162 & KPL-1 & BTNMG & BTNMG & BTNMG & BTNMG & BTNMG \\
\hline CD163 & GHI/61 & M & MG & MG & & $\mathrm{G}$ \\
\hline CD164 & 67D2 & BTNMG & BTNMG & BTNMG & BTNMG & BTNMG \\
\hline CD165 & SN2 (N6-D11) & BTNMG & BTNMG & $B$ & BTNMG & BTNMG \\
\hline CD166 & $3 \mathrm{~A} 6$ & BTNMG & BTNMG & BT MG & BT MG & BTNMG \\
\hline CD167a & 51D6 & & & & & \\
\hline CD169 & $7-239$ & & & & & \\
\hline CD170 & 1A5 & NMG & & & & \\
\hline CD172a & SE5A5 & T MG & T MG & TNMG & MG & MG \\
\hline CD172b & B4B6 & MG & & & & \\
\hline CD172g & LSB2.20 & $\begin{array}{ll}T & G \\
\end{array}$ & MG & TNMG & TNMG & MG \\
\hline CD178 & NOK-1 & G & & & MG & \\
\hline CD179a & HSL96 & & & & & $T$ \\
\hline CD179b & HSL11 & & & & & BT M \\
\hline CD180 & MHR73-11 & B $M$ & B $\quad M$ & B $M$ & B $\quad M$ & B \\
\hline CD181 & 8F1/CXCR1 & TNMG & & & & \\
\hline CD182 & 5E8/CXCR2 & NMG & & & & \\
\hline CD183 & G025H7 & BTNMG & BTNMG & BTNM & BTNMG & BTNMG \\
\hline CD184 & $12 \mathrm{G} 5$ & BTNMG & BTNMG & BTNMG & BTNMG & BTNMG \\
\hline CD193 & 5E8 & T M & & & & \\
\hline CD195 & $\mathrm{T} 21 / 8$ & BTNMG & T MG & MG & $\mathrm{T} \mathrm{M}$ & T MG \\
\hline CD196 & G034E3 & BTNM & BTN G & BTN & BTN & BTNMG \\
\hline CD197 & G043H7 & BT $\quad G$ & BT & BT & BTN & BT \\
\hline CD200 & OX-104 & BT $\quad G$ & & & BT & $B$ \\
\hline CD200R & OX-108 & BTNMG & & & BT MG & \\
\hline CD201 & RCR-401 & & & & & \\
\hline CD202b & 33.1 (Ab33) & & & & & \\
\hline CD203c & NP4D6 & & & & & \\
\hline CD205 & HD30 & G & BT MG & T MG & T MG & TNMG \\
\hline CD206 & $15-2$ & & & & & \\
\hline CD207 & 10E2 & & & & & \\
\hline CD209 & 9E9A8 & & & & & \\
\hline CD210 & $3 F 9$ & BTNMG & BTNM & M & BTN & BTNMG \\
\hline CD213a2 & SHM38 & T G & & $\mathrm{T}$ & & \\
\hline CD215 & JM7A4 & $\begin{array}{ll}T & G \\
\end{array}$ & $T \quad G$ & TN G & $\mathrm{T} \quad \mathrm{G}$ & $T \quad G$ \\
\hline CD218a & $\mathrm{H} 44$ & TNMG & $\mathrm{N}$ & $\mathrm{TN}$ & $\mathrm{TN}$ & TN G \\
\hline CD220 & B6.220 & M & MG & M & M & MG \\
\hline CD221 & 1H7/CD221 & TNMG & T MG & $\mathrm{T}$ & BTN G & $\mathrm{NG}$ \\
\hline CD226 & 11A8 & BTNMG & BTNMG & BTNMG & BTNMG & BTNMG \\
\hline CD229 & HLy-9.1.25 & BTN & & & & \\
\hline CD231 & SN1a (M3-3D9) & $T \quad G$ & G & & $T$ & $T$ \\
\hline CD235ab & HIR2 & & & & & B \\
\hline CD243 & UIC2 & BTNMG & & & $T$ & $\mathrm{~T}$ \\
\hline CD244 & $\mathrm{C} 1.7$ & TNM & & & & \\
\hline CD245 & DY12 & TNMG & M & & $\mathrm{TN}$ & $M$ \\
\hline CD252 & 11C3.1 & G & & & & T G \\
\hline CD253 & RIK-2 & TN G & & & & $\mathrm{N}$ \\
\hline CD254 & $\mathrm{MIH} 24$ & G & & & & \\
\hline CD255 & CARL-1 & & & & $T$ & $T$ \\
\hline CD257 & T7-241 & BT MG & $T \quad G$ & TN G & T MG & BT MG \\
\hline CD258 & T5-39 & & & TN & & \\
\hline CD261 & DJR1 & G & $\mathrm{T}$ & & & $\mathrm{T}$ \\
\hline CD262 & DJR2-4 (7-8) & T MG & & & & \\
\hline
\end{tabular}

\begin{tabular}{|c|c|c|c|c|c|c|}
\hline Antibody & Clone & Human & Cyno & Rhesus & Baboon & AGM \\
\hline CD263 & DJR3 & G & & & & \\
\hline CD266 & ITEM-1 & & & & & $T$ \\
\hline CD267 & 1A1 & B & B & B & B & B \\
\hline CD268 & $11 \mathrm{C1}$ & BT & BT M & B & BT MG & BT MG \\
\hline CD271 & ME20.4 & $\mathrm{N}$ & TNM & TNM & BTNM & TNM \\
\hline CD272 & MIH26 & BT & & & & $\mathrm{G}$ \\
\hline CD273 & $24 \mathrm{~F} .10 \mathrm{C} 12$ & $\begin{array}{ll}T & G \\
\end{array}$ & TNM & TNM & T M & M \\
\hline CD274 & 29E.2A3 & BTNMG & $\begin{array}{ll}T & G \\
\end{array}$ & N G & T MG & BTNMG \\
\hline CD275 & 9F.8A4 & $B$ & & & & \\
\hline CD276 & MIH42 & TN G & $\mathrm{N}$ & $\mathrm{N}$ & & TN \\
\hline CD277 & BT3.1 & BTNMG & B & $B$ & BTNM & BTN \\
\hline CD278 & C398.4A & TN & $T$ & $T$ & $T$ & $T$ \\
\hline CD279 & EH12.2H7 & $T$ & $T$ & $T$ & $T$ & $T$ \\
\hline CD282 & TL2.1 & B $\quad$ MG & & & & \\
\hline CD284 & HTA125 & T M & & & & \\
\hline CD286 & TLR6.127 & MG & & & & \\
\hline CD290 & $3 \mathrm{C} 10 \mathrm{C} 5$ & $B$ & & & $B$ & \\
\hline CD294 & BM16 & MG & & & & \\
\hline CD298 & LNH-94 & BTNMG & BTNMG & BTNMG & BTNMG & BTNMG \\
\hline CD300e & UP-H2 & M & & & & \\
\hline CD300F & UP-D2 & M & & & & \\
\hline CD301 & H037G3 & BT MG & T MG & & BT MG & BT MG \\
\hline CD303 & $201 \mathrm{~A}$ & & & & & \\
\hline CD304 & $12 \mathrm{C} 2$ & & & & & \\
\hline CD307e & $509 f 6$ & B & & & & \\
\hline CD314 & 1D11 & TN G & TN & $\mathrm{TN}$ & $\mathrm{TN}$ & $\mathrm{N}$ \\
\hline CD317 & RS38E & BTNMG & BTNMG & BTNM & BTNMG & BTNMG \\
\hline CD318 & CUB1 & & & & & \\
\hline CD319 & 162.1 & BTNM & G & & & \\
\hline CD324 & 67A4 & & & & & \\
\hline CD325 & $8 \mathrm{C} 11$ & G & & & & \\
\hline CD326 & $9 \mathrm{C} 4$ & & & & & \\
\hline CD328 & $6-434$ & NMG & & & & \\
\hline CD334 & 4FR6D3 & & & & & \\
\hline CD335 & $9 \mathrm{E} 2$ & $\mathrm{~N}$ & & & & \\
\hline CD336 & P44-8 & & & & & \\
\hline CD337 & P30-15 & $\mathrm{N}$ & $\mathrm{N}$ & $\mathrm{N}$ & $\mathrm{N}$ & $\mathrm{N}$ \\
\hline CD338 & 5D3 & & & & & \\
\hline CD340 & 24D2 & & & & & \\
\hline CD344 & CH3A4A7 & TNMG & & & & TN G \\
\hline CD351 & TX61 & $\mathrm{NG}$ & & & & \\
\hline CD352 & NT-7 & BTNMG & T MG & & T G & $T$ \\
\hline CD354 & TREM-26 & TNMG & MG & $\begin{array}{ll}T \quad G \\
\end{array}$ & MG & $\mathrm{G}$ \\
\hline CD355 & Cr24.1 & & & & & \\
\hline CD357 & 621 & TNMG & T $\quad G$ & TN G & $T \quad G$ & T MG \\
\hline CD360 & 2G1-K12 & BTNM & BTNM & BTNM & BTNM & B NM \\
\hline 4-1BB Ligand & $5 \mathrm{~F} 4$ & TNMG & $\begin{array}{ll}T & G \\
\end{array}$ & TN & $\begin{array}{ll}T & G\end{array}$ & TNMG \\
\hline C3aR & hC3aRZ8 & TNMG & & & & \\
\hline C5L2 & 1D9-M12 & TNMG & BTNMG & BTNMG & BTNMG & BTNMG \\
\hline CCR10 & $6588-5$ & BTNMG & B $\quad$ MG & BTNMG & BT MG & BT MG \\
\hline CLEC12A & $50 \mathrm{C} 1$ & MG & & & & \\
\hline CLEC9A & $8 \mathrm{F9}$ & & & & & \\
\hline CX3CR1 & $2 \mathrm{~A} 9-1$ & TNMG & MG & G & & M \\
\hline CXCR7 & 8F11-M16 & & & & & \\
\hline Delta Opioid & DOR7D2A4 & & & & & \\
\hline Receptor & & & & & & \\
\hline DLL1 & MHD1-314 & & & & & \\
\hline DLL4 & MHD4-46 & & & & & \\
\hline DR3 & JD3 & & & & & \\
\hline EGFR & AY13 & & & & & \\
\hline erbB3 & 1B4C3 & & & & & \\
\hline FCRL4 & 413D12 & & & & & \\
\hline FcRL6 & $2 \mathrm{H} 3$ & $\mathrm{~N}$ & & & & B \\
\hline FceRla & AER-37 (CRA-1) & M & $M$ & M & $M$ & \\
\hline Galectin-9 & $9 \mathrm{M} 1-3$ & $T \quad G$ & BT $\quad G$ & & BT $\mathrm{G}$ & $T$ \\
\hline GARP & 7B11 & & & & & \\
\hline HLA-A2 & BB7.2 & & & & & \\
\hline HLA-A,B,C & W6/32 & BTNMG & BTNMG & BTNMG & BTNMG & BTNMG \\
\hline HLA-DQ & HLADQ1 & $B$ & & & & \\
\hline HLA-DR & L243 & BTNM & B $\quad$ MG & BTNMG & BTNMG & BTNMG \\
\hline HLA-E & $3 \mathrm{D} 12$ & BTNMG & & & & \\
\hline HLA-G & $87 \mathrm{G}$ & & MG & MG & & $M$ \\
\hline HVEM & 122 & BTNMG & BTNMG & BTNM & BTNMG & BTNMG \\
\hline IFN- $\gamma$ R b chain & 2HUB-159 & T MG & G & $T$ & $\mathrm{~T}$ & T MG \\
\hline
\end{tabular}


bioRxiv preprint doi: https://doi.org/10.1101/577759; this version posted March 14,2019 . The copyright holder for this preprint (which was not certified by peer review) is the author/funder. All rights reserved. No reuse allowed without permission.

\begin{tabular}{|c|c|c|c|c|c|c|}
\hline Antibody & Clone & Human & Cyno & Rhesus & Baboon & AGM \\
\hline $\lg \mathrm{D}$ & IA6-2 & B & & & & \\
\hline IgG1, k Isotype Ctrl & MOPC-21 & & & & & \\
\hline IgG1, k Isotype Ctrl & RTK2071 & & & & & \\
\hline $\begin{array}{l}\text { IgG2a, k Isotype } \\
\text { Ctrl }\end{array}$ & MOPC-173 & & & & & \\
\hline $\begin{array}{l}\text { IgG2a, k Isotype } \\
\text { Ctrl }\end{array}$ & RTK2758 & & & & & \\
\hline $\begin{array}{l}\text { IgG2b, k Isotype } \\
\text { Ctrl }\end{array}$ & MPC-11 & & & & & \\
\hline $\begin{array}{l}\text { IgG2b, K Isotype } \\
\text { Ctrl }\end{array}$ & RTK4530 & & & & & \\
\hline IgG3,k Isotype Ctrl & MG3-35 & & & & & \\
\hline IgG Isotype Ctrl & HTK888 & & & & & \\
\hline Ig light chain $\mathrm{K}$ & MHK-49 & B $\quad$ MG & $\mathrm{G}$ & & & \\
\hline Ig light chain $\lambda$ & MHL-38 & B $M$ & B $\quad$ MG & B $\quad$ MG & B $\quad$ MG & \\
\hline $\lg M$ & MHM-88 & B NMG & B $\quad$ MG & B NMG & BTNMG & BTNMG \\
\hline IgM, k Isotype Ctrl & MM-30 & & & & & \\
\hline IgM, k Isotype Ctrl & RTK2118 & & & & & \\
\hline IL-28RA & MHLICR2a & & & & & \\
\hline Integrin $\alpha 9 \beta 1$ & Y9A2 & MG & $G$ & $\mathrm{~N}$ & $\mathrm{~N}$ & $\mathrm{~N} \mathrm{G}$ \\
\hline integrin $\beta 5$ & AST-3T & & $G$ & & & \\
\hline Integrin $\beta 7$ & FIB504 & BTNMG & BTNM & BTNMG & BTNMG & BTNMG \\
\hline Jagged 2 & MHJ2-523 & $\mathrm{N}$ & & & & \\
\hline LAP & TW4-6H10 & $M$ & MG & & $M$ & $T M$ \\
\hline $\begin{array}{l}\text { Lymphotoxin } \beta \\
\text { Receptor }\end{array}$ & 31G4D8 & $M$ & $M$ & M & & BT MG \\
\hline Mac-2 & Gal397 & $\mathrm{T} \quad \mathrm{G}$ & $\mathrm{T} \quad \mathrm{G}$ & & $\mathrm{T} \quad \mathrm{G}$ & $\mathrm{T} \quad \mathrm{G}$ \\
\hline MAIR-II & TX45 & ????? & $\mathrm{T} \quad \mathrm{G}$ & $\mathrm{T}$ & $\mathrm{T}$ & $\mathrm{T} \quad \mathrm{G}$ \\
\hline MICA/MICB & 6D4 & & & & & \\
\hline MSC & W7C6 & $\mathrm{T}$ & $\mathrm{T}$ & $\mathrm{T} \quad \mathrm{G}$ & $T M$ & $T$ \\
\hline MSC,NPC & W4A5 & BT MG & $\mathrm{T} \quad \mathrm{G}$ & BTNMG & BT MG & BT MG \\
\hline NKp80 & 5D12 & $\mathrm{N}$ & TN & TNM & TNM & TN \\
\hline Notch 1 & MHN1-519 & $\mathrm{N}$ & & & & \\
\hline Notch 2 & MHN2-25 & $M$ & & & & $M$ \\
\hline Notch3 & MHN3-21 & & & & & \\
\hline Notch 4 & MHN4-2 & & & & & \\
\hline NPC & 57D2 & ????? & & & & $\mathrm{T}$ \\
\hline Podoplanin & NC-08 & & & & & \\
\hline Pre-BCR & HSL2 & MG & $M$ & $M$ & & \\
\hline PSMA & LNI-17 & & & & & \\
\hline Siglec-10 & $5 \mathrm{G} 6$ & B $M$ & & & & MG \\
\hline Siglec-8 & $7 C 9$ & $\mathrm{~N}$ & & & & \\
\hline Siglec-9 & $\mathrm{K} 8$ & NMG & & & & \\
\hline SSEA-1 & MC-480 & G & & & & \\
\hline SSEA-3 & MC-631 & & & & & B \\
\hline SSEA-4 & MC-813-70 & & MG & $\mathrm{G}$ & G & \\
\hline SSEA-5 & $8 \mathrm{E} 11$ & $\mathrm{~T}$ & & & & $T$ \\
\hline SUSD2 & W3D5 & B & & TN & & BT MG \\
\hline SUSD2 & W5C5 & $\mathrm{N}$ & TNM & & G & BTNMG \\
\hline TCR gamma/delta & B1 & $\mathrm{T} \quad \mathrm{G}$ & $\mathrm{T}$ & $\mathrm{TN}$ & $\mathrm{TN}$ & $\mathrm{T}$ \\
\hline TCR Va24-Ja18 & 6B11 & & & & & \\
\hline TCR Va7.2 & $3 C 10$ & $\mathrm{~T}$ & & & & \\
\hline TCR V $\beta 13.2$ & $\mathrm{H} 132$ & ????? & & & & \\
\hline TCR V $\beta 23$ & aHUT7 & & & & & \\
\hline TCR V $\beta 8$ & JR2 (JR.2) & & & & & \\
\hline TCR V $\beta 9$ & MKB1 & & & & & \\
\hline TCR V $\delta 2$ & B6 & & & & & \\
\hline $\mathrm{TCR} \alpha / \beta$ & IP26 & $\mathrm{T}$ & & & & \\
\hline Tim-1 & 1D12 & $\mathrm{N} \mathrm{G}$ & & & & \\
\hline Tim-3 & F38-2E2 & $\mathrm{N}$ & & & & \\
\hline Tim-4 & 9F4 & & & & & \\
\hline TLT-2 & MIH61 & ????? & & & & \\
\hline TNAP & W8B2 & G & $\mathrm{G}$ & & B $\quad$ MG & B \\
\hline TRA-1-60-R & TRA-1-60-R & & & & & \\
\hline TRA-1-81 & TRA-1-81 & $\mathrm{N}$ & & & & \\
\hline TSLPR & 1B4 & & & & $M$ & \\
\hline$V_{\gamma} 9$ & B3 & & & & & \\
\hline$\beta 2$-microglobulin & $2 \mathrm{M} 2$ & BT?MG & $\mathrm{B} \mathrm{N}$ & B & B & B \\
\hline
\end{tabular}

